\title{
Construction on Multivariate Evaluation System for Aerobics in Teaching mode of Rotational Classroom
}

\author{
Ying Zhang \\ College of Education and Sports, Bohai University, Jinzhou, 121013, China \\ 47086132@qq.com
}

Keywords: rotational classroom; teaching mode; aerobics; multivariate evaluation system

\begin{abstract}
Rotational classroom" is new classroom teaching mode to develop thinking skills, innovation and practical ability as the core for students. Multivariate evaluation is based on multivariate intelligence theory, multi-disciplinary assess student learning outcomes. In this study, from the multivariate teaching evaluation perspective, focuses on elaborating the significance of the construction of multivariate evaluation system for aerobics, and combined the teaching philosophy of rotational classroom with multivariate teaching evaluation, construct multivariate evaluation system for aerobics under the "rotational classroom" teaching model, design specific evaluation content. It aimed at resolving the problem of bottlenecks in the traditional classroom teaching evaluation, and achieving the reengineering of learning process and the extension of teaching space, the highlighting the students' learning autonomy.
\end{abstract}

\section{Introduction}

Teaching evaluation is based on that the teaching objectives value and judge the teaching results and process and serviced for teaching decision-making activities, is the process of teaching actual or potential value judgment, generally including the process of teaching teachers, students, teaching content, teaching methods, teaching environment, teaching management evaluation of various factors, but mainly the evaluation of student learning and teachers teaching evaluation process [1]. Teaching evaluation as an important part of the teaching process, to promote learning outcomes, but also to guide students to learn to cultivate the right direction and learning attitude and to detect students' overall learning outcomes, lack of diagnostic study guide direction for students, so teachers should be evaluated and Teaching target combination, taking pluralistic way to assess student learning outcomes, improved teachers. Multivariate teaching evaluation is to promote and protect the students' innovative quality development as its basic values and core objectives, multivariate intelligences theory; it inherited the outstanding achievements of modern educational evaluation, summary, reference, developed the goals teaching and developmental evaluation research results [2].

\section{Research Significance}

Multivariate teaching evaluation theory refers to that the evaluation methods should be diverse, summative and formative assessment should be combined, which includes not only the teacher evaluation should also include student peer assessment, student self-assessment; evaluation includes not only the amount, but also including qualitative evaluation [3]. Aerobics professional student performance evaluation system evaluation theory of multivariate teaching aerobics majors based on academic research object to the basic idea of multivariate intelligences theory, the students have learned during the school curriculum aerobics process and results do a scientific judgment process. The main purpose of the concept of teaching evaluation multivariate advocate both be true, but also diversification; both should be combined with the contents of the activities, but also to focus on students' individual differences and their own advantages as the center; both summative importance, but also pay attention to the process of evaluation. Designed to meet the diverse needs of the community, achieve significant role in promoting professional training of aerobics. The study meaning as follows: 
(1) Thoroughly implement the guiding ideology of the ministry of education; comprehensively promote the needs of our school practice teaching. Ministry of Education, "Opinions on Further Deepening the reform of undergraduate teaching and comprehensively improve the quality of teaching," clearly states that "to enhance the quality of higher education, personnel training is the core, undergraduate teaching is the key. To increase investment in education, deepen the teaching reform, promote personnel training model innovation, strengthen experiment, practice, graduation design practice teaching. "[4]. Thus, improving students' practical capacity has become important and difficult teaching development. My school based on the school's training objectives, learn from the advanced science classroom teaching proposed to students thinking skills, new classroom teaching mode innovation and practical ability as the core of the "rotation of the classroom," one of the "transfer "mainly includes the transfer of classroom teaching ideas and teaching methods, covering three meanings: the first transition from the traditional classroom teaching with knowledge transfer center, changed to develop students' thinking skills, creative ability, practical ability as the center; the second transfer method, teaching methods from the traditional indoctrination, cramming into a heuristic, inquiry, discussion and case type; the third twist, the classroom teacher from the traditional body into a student-centered [ 5]. Therefore, this project is the attempt to train under the guidance of a powerful spiritual guidance to carry out the above my school talent. Actively strengthen practice teaching, to carry out the practice of teaching reform "rotational classroom" teaching mode, explore the methods and measures aerobics training students practical ability, attention to outstanding students professional skills application ability, social adaptability, learning capacity development practical ability and innovation ability.

(2) Achieved the "education process reengineering, teaching space extension", highlights the need for independent learning. From the perspective of the teaching process, turn the classroom to subvert the traditional "on Teachers teach + after-school students practice" of the teaching process, "which is rotated by the rotation of the rotation center of gravity of the role of teachers, classroom agenda-setting function, etc., The time element of classroom teaching (pre-class and middle class), spatial features (extracurricular and curricular), personnel (teachers and students) behavior and performance elements, media elements (resources, tools) and other readjustment program, Convergence, to achieve a reasonable element of coordination, fine fully functioning organization, process, and ultimately improve the effectiveness of teaching, so that students learn the value of the subject has been highlighted and emphasized [6]. At the same time, turn the classroom will extend the original limited class time to the previous lesson requires students before class to watch instructional videos, independently of basic knowledge. Students after class to watch instructional videos can also communicate over the network when they encounter problems with teachers and peers for help. Such learning atmosphere more relaxed, student learning initiative further implementation.

(3) Address the needs of bottlenecks in traditional classroom teaching evaluation. The traditional teaching model is to impart style, its structure "talk, listen, read, write, practice", is characterized explain instill knowledge, the students passively accept knowledge, this teaching model for teachers because it is easy to grasp the progress of teaching, classroom knowledge information Large, high "teaching" efficiency and been adopted by many teachers [7]. The disadvantage is the teacher teaches based teaching model, ignoring the students 'ability to accept different, ignoring students' individual requirements, making the students lose rights as a subject of study, leading to student motivation, learning outcomes are difficult to improve the quality of learning . Compared with the traditional teaching mode, rotational classroom has the advantage of breakthrough teaching limitations, reconstruction teaching structure, proposed advantages of the new teaching ideas and other aspects. Rotational classroom mode from the knowledge taught by teachers become facilitators of student learning, teachers need to change the traditional concept of teaching evaluation, it is necessary to pay attention to the results, but also to focus on the process. In the evaluation of students 'knowledge and ability, we must also focus on the development of students' emotions, attitudes, values and other aspects; to gradually establish methods varied, quantitative and qualitative study evaluation system, and create a student-centered teaching and evaluation 
environment allow students to learn more effectively involved in the evaluation process, in teaching the students really empowerment so that they learn self-control, self-reflection, and truly become the main body of learning.

(4) Strengthen macro-design, the need specialized guidance and monitoring. Rotational classroom learning help teachers evaluate student learning supervise and inspect, identify problems and deficiencies that exist in student learning, suggest improvements and methods. For clear whether the rotational classroom teaching to achieve the desired teaching objectives, whether student learning and to be useful for student learning for value judgments, promoting education has an important role in deepening the reform. Rotation of classroom teaching model to break the traditional teaching pattern, with evaluation of the main diversification, diversification of evaluation of the content of a comprehensive evaluation of the characteristics of an angle, so that lesson and lesson teaching function under replacement form extending more classroom time and space, more teaching role of participation, multi-channel way to learn characteristics [8]. Therefore, in my school full implementation rotate the classroom teaching reform, to deal with students for specialized guidance and monitoring, strengthening the teaching evaluation design highlights important. Through student self-assessment, teacher evaluation, in-room companion group peer assessment and group assessment, etc., to promote the effective realization of student learning, improve student learning autonomy.

\section{Multivariate Evaluation Process}

The process of fully implement multivariate evaluation under the "rotational classroom" model as follows:

(1) Diagnostic evaluation before class. Diagnostic assessment of learning outcomes before the class is to rotate the classroom before class exercises were evaluated. Watch the video before class rotational classroom learning process is different from the traditional method of teaching an important stage. Check this stage of learning outcomes for the students of the follow-up study has an important effect on the process of teaching teachers also have an important role in promoting. Early evaluation can be used with the task of instructional videos that came with the job the way, a check and the results recorded in the comprehensive evaluation of the way the table can also be used when a simple test class.

(2) Procedural evaluation in the classes. Procedural evaluation in the classes is in the form of the "student and student assessment" the collaborative team learning outcomes as a basis for evaluation of performance. Among the team members are in the form of the mutual evaluation to determine students' initiative, enthusiasm, creativity and personal expression, reaction capability [9]. Evaluation can score the way; it can also be used in a hierarchical manner. Used in the rotation of the classroom to facilitate collaborative learning among students discuss with each other, explore learning problems, in discussions to explore not only to learn the knowledge, but also can improve students' ability to communicate and develop interpersonal relationships between students. Students in the classroom to explore issues through an independent, cooperative group learning; to solve the difficult problems existed before class.

(3) Summative evaluation after-school. Summative evaluation is also known as summative, is evaluated to understand the ultimate effect of teaching activities carried out. Turning classroom teaching, teachers demonstrated for students in the classroom learning process knowledge internalization capability, reflecting learning ability and learning individuals. Exam as an important method to reflect learning outcomes remain essential, but still for the test content and format adapt and adjust teaching mode, and only the final grade in the appropriate proportion of the total score.

\section{Framework Structure on Multivariate Evaluation System}

Reversed the order of rotation of the classroom as well as a series of learning activities arranged so that teachers and students before class learning phase is in a relatively isolated situation. Without teachers to students face to face with real-time monitoring of radiation or authority, learning to 
become totally dependent on student motivation, self-awareness. Thus, the rotation of classroom learning needs stronger constraint mechanism, monitoring mechanism to ensure the quality of learning. A more comprehensive assessment of students; learning outside the classroom monitoring to supervise students' basic learning tasks completed: to promote the autonomy of student learning to play a form of consciousness and autonomy for the purpose of learning assessment designed mainly for its specific objectives in class learning, improve teaching strategies [10]. Framework structure on multivariate evaluation system as shown in Fig. 1.

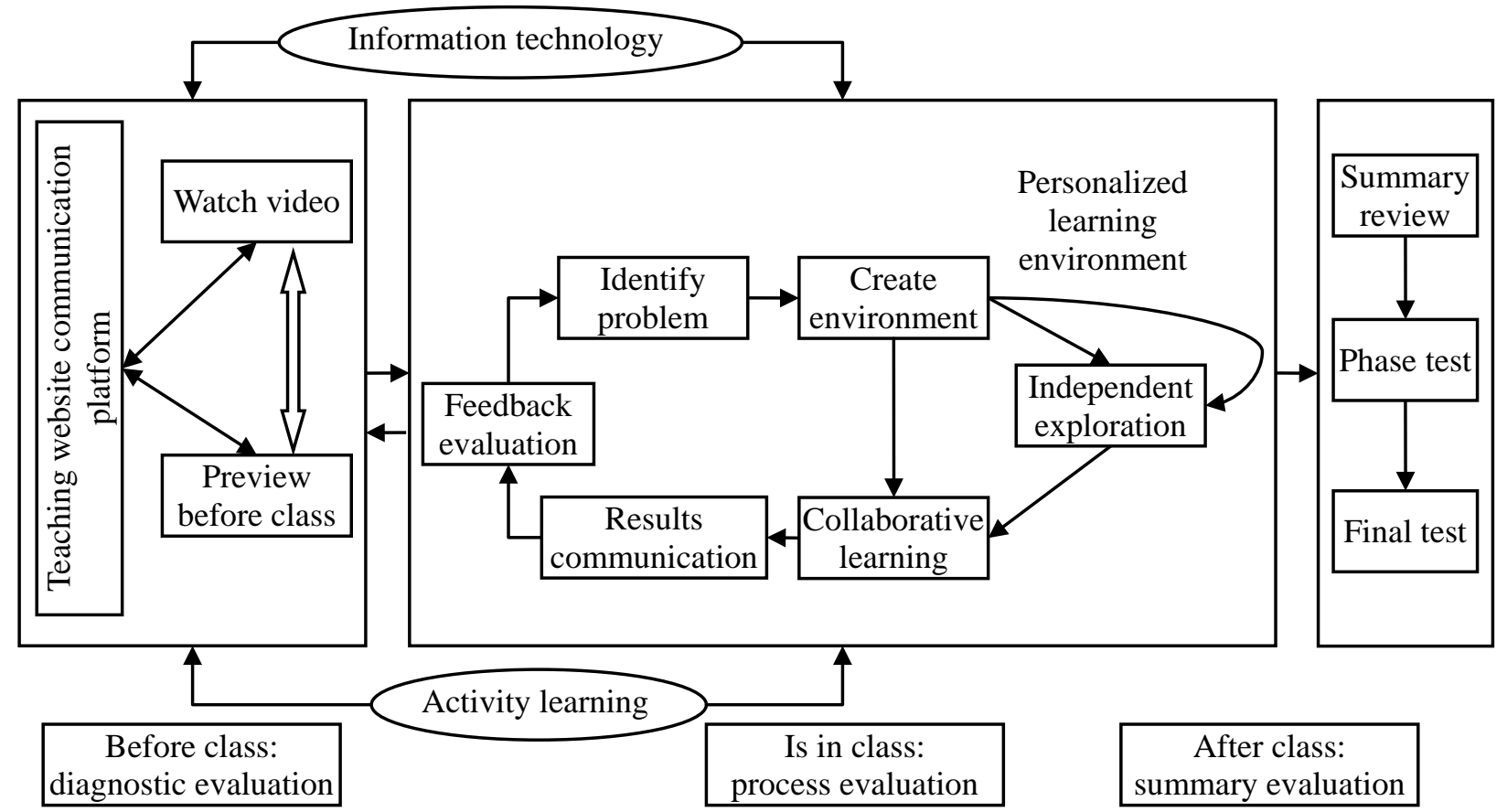

Fig. 1. Framework structure on multivariate evaluation system

(1) Learning phase before lesson. Students to self-study aerobics using watch the video, to complete the traditional classroom teachers in the teaching of knowledge through learning. Learning of this phase will be mainly in the instructional video learning readiness, learning attitude, the degree and level of study within several aspects. At the same time, turning the classroom teaching mode, students need to learn website on heat exchange platforms to find problems with their teacher or student exchanges, so as to complete the study on the network platform, the number of students to ask questions and level of participation in the discussion by, learn contribution for others to do so can be a true record of student learning, not only reflects the quality of learning, to better reflect the enthusiasm for learning, students shared sense of team spirit and win.

(2) Learning phase in lesson. In the rotational classroom teaching mode, teachers in the classroom will be organized students to independent learning, collaborative learning and research exchanges. First, the teacher in the teaching process to determine the problem by urging students to explore the problem, so that students can learn in an independent study to knowledge and solve problems. Through this study, students of independent learning ability can be improved. Independent learning problems driven by including analysis of the problem, determine the sub-problems to be solved to resolve the issue should be completed, to find information to solve the sub-problems, come to solutions other steps. Secondly, collaborative learning is the use of dialogue between individuals, discuss, debate and other forms fully demonstrated by the research questions to get way to achieve learning objectives. Early learning outcomes students use collaborative learning and team members, and promote each other through discussions, etc., to exchange learning outcomes, increasing the depth and breadth of learning content operations. In addition, students will need in the classroom group as a unit of learning outcomes reporting display, determine their own shortcomings and problems in learning the results of the exchange process, to further improve learning outcomes, and the teams to communicate and share learning. Teachers play learning organization, guiding role in class, and to answer questions. Display and exchange students through 
achievement, not only to consolidate the lesson learned knowledge, but also to cultivate students' communication ability, skills, etc., so that the overall quality of students improved.

(3) Learning phase after-school. The main task of after-school learning is a summary of the previous stage of the learning process, conducted every lesson phase of testing, final test to complete the entire course. The process for school teachers demonstrated the ability to evaluate knowledge internalization learning ability and learning.

\section{Design on Multivariate Evaluation System}

Based on the feature of rotational classroom teaching model, the teaching model of learning evaluation can be summarized as the evaluation system of project-level evaluations, secondary and tertiary project evaluation project evaluation. The evaluation of learning outcomes based on the contribution rate, the proportion of the appropriate allocation. Turning the classroom teaching process, where students watch instructional videos before learning evaluation, independent learning process in class performance and collaborative learning process performance evaluation of the proportion of larger, while the proportion of other items are relatively less, the content of the specific design of the evaluation index as shown in Table 1. 
Table 1. Multivariate evaluation system for aerobics in teaching mode of rotational classroom

\begin{tabular}{|c|c|c|c|}
\hline & First level index & $\begin{array}{l}\text { Second level } \\
\text { index }\end{array}$ & Third level index \\
\hline \multirow{7}{*}{$\begin{array}{l}\text { Before } \\
\text { class }\end{array}$} & \multirow{6}{*}{$\begin{array}{c}\text { Independently watch the } \\
\text { instructional video learning } \\
(20 \%)\end{array}$} & \multirow{2}{*}{$\begin{array}{l}\text { Preview } \\
\text { situation }\end{array}$} & Whether preview related to teaching content \\
\hline & & & Whether to find relevant teaching materials \\
\hline & & \multirow{2}{*}{ Watch situation } & Whether completely watch the instructional video \\
\hline & & & In the process of watching the video whether record \\
\hline & & \multirow{2}{*}{$\begin{array}{l}\text { Feedback } \\
\text { situation }\end{array}$} & Whether propose question after watching the video \\
\hline & & & Whether practice after watching the video \\
\hline & $\begin{array}{l}\text { Interactive exchange of } \\
\text { information on teaching } \\
\text { website platform }(10 \%) \\
\end{array}$ & \multicolumn{2}{|c|}{ In the standard of exchange situation on the teaching web platform } \\
\hline \multirow{18}{*}{$\begin{array}{l}\text { Is in } \\
\text { class }\end{array}$} & \multirow{3}{*}{$\begin{array}{c}\text { Performance of in the } \\
\text { process of independent } \\
\text { learning in classroom (20\%) }\end{array}$} & & Whether independent analysis the problem \\
\hline & & & Whether independently find information \\
\hline & & & Whether independently propose solutions \\
\hline & \multirow{12}{*}{$\begin{array}{c}\text { Performance in the process } \\
\text { of collaborative learning in } \\
\text { classroom }(30 \%)\end{array}$} & \multirow{3}{*}{$\begin{array}{l}\text { Cooperative } \\
\text { attitude }\end{array}$} & Whether attitude is enthusiastic \\
\hline & & & Whether actively participate in a panel discussion \\
\hline & & & Whether humbly adopt the opinions of others \\
\hline & & \multirow{2}{*}{$\begin{array}{l}\text { Completion } \\
\text { status }\end{array}$} & Whether complete undertaken tasks \\
\hline & & & Whether provide advice to others \\
\hline & & \multirow{3}{*}{$\begin{array}{l}\text { Coordination } \\
\text { condition }\end{array}$} & Whether tacit in collaboration \\
\hline & & & Whether able to discuss with others \\
\hline & & & Whether listened carefully to the views of others \\
\hline & & \multirow{2}{*}{ Communication } & Whether actively communicate with others \\
\hline & & & Whether exchange content is related to the course \\
\hline & & \multirow{2}{*}{ Task division } & Whether panel members division are clear \\
\hline & & & Whether to allocate according to interest capacity \\
\hline & \multirow{3}{*}{$\begin{array}{l}\text { Exhibition and } \\
\text { communication on the } \\
\text { achievements in the } \\
\text { classroom }(10 \%)\end{array}$} & \multirow{3}{*}{ Results show } & Whether the content of results show is accurate and clear \\
\hline & & & Whether the results show is fun \\
\hline & & & $\begin{array}{l}\text { Whether the results show is the exchange between the two } \\
\text { groups }\end{array}$ \\
\hline $\begin{array}{l}\text { After } \\
\text { class }\end{array}$ & After class testing (10\%) & & Reference standard test mode evaluation standard \\
\hline
\end{tabular}

\section{Conclusion}

"Rotational classroom" requires teachers to re-adjust teaching program, elaborate instructional videos, etc.; mostly need to monitor and guide the study situation for students. Thus, the multivariate evaluation theory into "rotational classroom" among the students learning evaluation design is more important. This research is a new attempt in the field of teaching evaluation under the "rotational classroom" teaching mode, despite take the standardized research methodology to establish an index system, but due to the limit of conditions from various objectives study, the scientific of index system remains to be further testing for practice. 


\section{Acknowledgement}

This work is supported by 2015 Bohai University teaching reform project: Research on Construction of Multivariate Evaluation System for Aerobics in Teaching mode of Rotational Classroom

\section{References}

[1] Baidu Encyclopedia, "Teaching evaluation," http://baike.baidu.com/link?url=mHi1YyPq-wMK6I1vua89CmG127WClgQZixbudz9v0ZEbcq ktmuZX8K9-z4NSwzbUUfY55gDPo5fqhY18tTfXA_, 2016-1-4.

[2] L. X. Li, "Research on the multi evaluation system of the public course of modern educational technology based on the normal students," Master's degree of Northwest Normal University, 2011.

[3] L. L. Wang, "Junior high school English teaching evaluation strategy construction and practice in Guyuan City Hui middle school as an example," Master's degree of ningxia teachers University, 2015.

[4] Ministry of Education, "Some opinions on further deepening the reform of undergraduate teaching and improving the teaching quality," http://baike.baidu.com/link?url=V1nOdLgsj8xWW3h1uVS1-N03h5sLuqXl8payKLyZotw7fUd LeHyFRn1hnKQOFvpzYVwHToPK9L0TMpx7kYei0K, 2016-1-4.

[5] L. Lin, Y. D. Yang, "Rotation class theory," Journal of Bohai University (Philosophy and Social Science Edition), vol. 37, no. 6, pp. 98-99, 2015.

[6] X. L. Mu, F. Q. Zhang, "Learning evaluation design of flipped classroom," Research on Curriculum Teaching, vol. 3, no. 11, pp. 24-25, 2015.

[7] Y. H. Wang, "Study on the learning evaluation of flipped classroom teaching mode," Teaching and management, vol. 31, no. 15, pp. 86-87, 2015.

[8] S. Lan, "Based on KLEE and fuzzy comprehensive evaluation operator cognitive ability assessment," Ergonomics, vol. 16, no. 1, pp. 30-31, 2010.

[9] Q. F. Guan, " Khan college flipped classroom," Shanghai education, vol. 14, no. 17, pp. 27-31, 2012.

[10] C. Y. Li, J. Gao, Y. X. Tang, et al, "Research on the evaluation system of flipped classroom teaching," Computer education, vol. 12, no. 11, pp. 101-102, 2015. 